Article

\title{
Effects of Grass and Forests and the Infiltration Amount on Preferential Flow in Karst Regions of China
}

\author{
Xiaoqing Kan ${ }^{1,2,3}$, Jinhua Cheng ${ }^{1,2, *}$, Xiaojing $\mathrm{Hu}^{4}$, Fangfang $\mathrm{Zhu}{ }^{1,2,3}$ and $\mathrm{Mu} \mathrm{Li}^{1,2,3}$ \\ 1 College of Soil and Water Conservation, Beijing Forestry University, Beijing 100083, China \\ 2 Key Laboratory of Soil and Water Conservation and Desertification Control of State Forestry Administration, \\ Beijing 100083, China \\ 3 Jianshui Research Station, School of Soil and Water Conservation, Beijing Forestry University, \\ No. 35 Qinghua East Road, Haidian District, Beijing 100083, China \\ 4 Beijing Water Science and Technology Institute, Beijing 100048, China \\ * Correspondence: jinhua_cheng@126.com; Tel.: +86-(0)10-6233-8040
}

Received: 16 May 2019; Accepted: 6 August 2019; Published: 8 August 2019

\begin{abstract}
Preferential flow is an important water infiltration phenomenon in karst regions. The response of preferential flow to vegetation restoration requires urgent investigation due to the special soil structure of karst regions. In order to study the effect of vegetation restoration on water movement in karst regions, four kinds of ponded water infiltration experiments were carried out in Pinus Yunnanensis plantation forestland, secondary forestland, and natural grassland. A brilliant blue dyeing experiment was conducted to visualize the distribution of water infiltration in soil (a total of 150 stained images from vertical soil slices). Results showed that the average depth of matrix flow in natural grassland was approximately six times those in plantation and secondary forestlands. An increase in matrix flow will have a negative effect on the development of preferential flow. Water transported in preferential flow paths affects the distribution of nutrients and organic matter in the soil. However, preferential flow in grassland can promote the accumulation of available nutrients, and preferential flow in plantations can inhibit the loss of organic matter. Preferential flow in grasslands and forest plantations is less than that in native forests soils. Preferential flow increases the percolation of water in soils. The effect is that preferential flow can obstructs water uptake by the roots under low rainfall conditions, and decreases surface runoff before soil saturation under high rainfall conditions. In the process of nutrient element migration, preferential flow has a good contribution, which is conducive to the migration and accumulation of elements required for surface vegetation growth. The contribution of preferential flow needs to be considered in studies on vegetation restoration planning and land degradation.
\end{abstract}

Keywords: preferential flow; dye tracer; variability analysis; karst; structural equation model

\section{Introduction}

The concept of preferential flow is different from that of matrix flow [1]. Water infiltration initially shows a wetting front parallel to the soil surface. This part is defined as matrix flow, which is classified as uniform flow [2]. Then, the wetting front becomes irregular with different water inflow velocities. This part is called preferential flow, which is classified as non-uniform flow [3,4]. Preferential flow is a ubiquitous soil water movement phenomenon [5]. Preferential flow refers to the uneven and rapid movement of water and solutes through porous media (typically soil). It is an important factor that increases soil water conservation [6] and groundwater recharge [7] because of spatial connectivity of soil [8], which has been studied by certain mathematical models [9]. Moreover, 
preferential flow, as an important part of soil water infiltration, can affect the transport of pollutants [10], thus influencing the capacity of the soil to buffer and filter [11]. Some studies have found that the concentration of water-borne pollutants is not uniform when they diffuse [12]; however, few studies have focused on whether the distribution of soil nutrients will change with water infiltration. The special soil structure in karst area will affect the soil macropores, thus affecting preferential flow and soil permeability [13]. Therefore, preferential flow can affect the transport of elements and conveyance system for groundwater [14], which are the key factors in vegetation restoration and land degradation [15]. In this work, we used Brilliant Blue dyed tracer [16] and digital image processing techniques to determine the marks and analyses the characteristics of preferential flow, respectively [17].

The rapid process of preferential flow reduces the water retention time [18]; in order to make a profound study about the law of water cycle and the practical significance of natural forest and artificial forest on bottom of slope, the geochemical processes and the mode of vertical leakage need to be investigated [19]. At present, most studies that focus on different water inputs have lots of effects on preferential flow under different soil architectures [1], land cover [20], and land use [21]. Several studies show that a large rainfall of short duration contributes to the occurrence of preferential flow [22]. Few studies on the transport of metal ion pollutants by preferential flow after rainfall [23] and snowpack [24] have been reported. Some mathematical models simulate the vertical movement process of solutes carried by water [25]. However, insufficient attention has been given to preferential flow and its influence on water and nutrient transport under different precipitation levels in situ simulation experiments. The reason for the importance of studying on preferential flow is that it can easily form karst rock desertification due to the fragile ecological environment in karst regions; moreover, its environmental capacity is small, its anti-interference ability is low, and its resistance to pollutant diffusion is poor [26], thereby seriously restricting the development of agroforestry. Therefore, the effect of preferential flow on soil nutrient elements for vegetation restoration requires urgent study. Preferential flow has attracted wide attention because of its widespread existence, and its significant impact on the environment. Preferential flow has been studied based on dye tracer [27], CT scan [28,29], penetration curve [30], permeameter [31], and mathematical model [32]. Among them, the dyeing tracer method has become the most widely used preferential flow research method because it can visually and clearly reflect the region through the dyeing water flows. As a dye tracer, Brilliant Blue can visually show the distribution of non-uniform flow (preferential flow) in soil [33].

The ecological environment in karst regions needs to be governed and restored immediately [34]. However, the high variability in the soil spatial structures increases the difficulty of vegetation restoration. The pore structure and water infiltration characteristics of the soil can be obtained indirectly by studying preferential flow dyeing areas. In order to study the response of different forest sources (plantation restoration forestland and secondary forest or grassland) to the soil environment in this area, and discuss the influence of plantation on soil, experiments were carried out on Pinus Yunnanensis plantation forestland, secondary forestland and grassland in Jianshui, Yunnan Province, and the secondary forestland and grassland were selected for the study of primitive vegetation communities. A man-made forest (e.g., Pinus Yunnanensis plantation forestland) comprises excellent native tree species because of its extremely drought-resistant, barrenness resistance, and fast-growing under any conditions.

On this basis, the characteristics of soil erosion in karst areas are further investigated, and the advantages and disadvantages of vegetation restoration in karst areas are evaluated. These practices can provide theoretical support for the prevention and control of rock desertification. Therefore, this study aims (1) to analyze the distribution of preferential flow in a typical stand origin and the characteristics of water preferential infiltration movement, (2) to study the response of preferential flow to precipitation amounts and (3) to determine the relationship between nutrient accumulation and preferential flow in different typical stand origins. 


\section{Materials and Methods}

\subsection{Site Description}

Field experiments were conducted in forest soil from July 2018 to August of 2018 in Yangjie Catchment $\left(102^{\circ} 55^{\prime} \mathrm{E}, 23^{\circ} 37^{\prime}-23^{\circ} 44^{\prime} \mathrm{N}\right)$ in the southwestern karst area of Jianshui Town in Yunnan Province, China. The karst regions in Southwest China are the largest continuous karst regions in the world [35]. We selected three typical forest lands (e.g., Pinus Yunnanensis plantation, secondary forestland, and natural grassland) at the foot of the slope. The landform is that of a typical karst basin. The altitude is 1350-1700 m. It is affected by the monsoons of the Southwest Indian Ocean, which can form distinct dry and wet seasons. The seasonal drought of this area is severe, indicating that the rainy season (May to October) is humid, and rainfall during the dry season (November to April of the following year) is scarce. The annual average temperature is $19.8^{\circ} \mathrm{C}$, and the annual average temperature of the land surface is $20.8^{\circ} \mathrm{C}$. The average annual sunshine hours are $2322 \mathrm{~h}$, and the average annual precipitation is $805 \mathrm{~mm}$. The plantation forestry was planted in 1985, and its recovery time has been more than 30 years. Thus, the forest soil structure is stable. Secondary forestland has been restored since 1970, and no human disturbance was observed in the secondary forestland and grassland. Basic descriptions of the experimental sites are provided in Tables 1 and 2.

Table 1. Basic situation of the experimental sites.

\begin{tabular}{|c|c|c|c|c|c|c|}
\hline $\begin{array}{l}\text { Site } \\
\text { Type }\end{array}$ & $\begin{array}{c}\text { Land } \\
\text { Coverage } \\
(\%)\end{array}$ & Main Plant Type & $\begin{array}{l}\text { Tree } \\
\text { Height } \\
\text { (m) }\end{array}$ & $\begin{array}{c}\text { Stand } \\
\text { Density (m) }\end{array}$ & $\begin{array}{c}\text { Stained } \\
\text { Images (-) }\end{array}$ & $\begin{array}{c}\text { Fields } \\
\text { Environmental } \\
\text { Photos (-) }\end{array}$ \\
\hline $\mathbf{P Y}^{1}$ & 65 & Pinus Yunnanensis & 7.20 & $2 \times 2$ & 50 & \\
\hline $\mathrm{SF}^{2}$ & 80 & $\begin{array}{l}\text { Quercus baronii Skan; } \\
\text { Rhamnus leptophylla } \\
\text { Schneid; Crataegus } \\
\text { cuneata; Pistacia } \\
\text { chinensis Bunge; } \\
\text { Coriaria nepalensis Wall }\end{array}$ & 5.90 & $3 \times 4$ & 40 & \\
\hline $\mathrm{G}^{3}$ & 95 & $\begin{array}{l}\text { Themeda triandra Forsk. } \\
\text { Var. Japonica (Willd.) } \\
\text { Makino }\end{array}$ & - & - & 60 & \\
\hline
\end{tabular}

${ }^{1}$ PY corresponds to Pinus Yunnanensis plantation forestland. ${ }^{2}$ SF correspond to secondary forestland. ${ }^{3} \mathrm{G}$ corresponds to natural grassland.

Table 2. Basic soil characteristics of the experimental sites.

\begin{tabular}{cccccccc}
\hline $\begin{array}{c}\text { Stand } \\
\text { Origin }\end{array}$ & $\begin{array}{c}\text { Total Soil } \\
\text { Porosity } \\
(\%)\end{array}$ & $\begin{array}{c}\text { Soil Capillary } \\
\text { Porosity (\%) }\end{array}$ & $\begin{array}{c}\text { Soil } \\
\text { Non-Capillary } \\
\text { Porosity (\%) }\end{array}$ & $\begin{array}{c}\text { Maximum } \\
\text { Water } \\
\text { Holding } \\
\text { Capacity (\%) }\end{array}$ & $\begin{array}{c}\text { Minimum } \\
\text { Water } \\
\text { Holding } \\
\text { Capacity (\%) }\end{array}$ & $\begin{array}{c}\text { Field Water } \\
\text { Holding } \\
\text { Capacity (\%) }\end{array}$ & $\begin{array}{c}\text { Soil Natural } \\
\text { Water } \\
\text { Content (\%) }\end{array}$ \\
\hline PY & $36 \pm 12^{1}$ & $35 \pm 13$ & $2 \pm 1$ & $32 \pm 19$ & $30 \pm 19$ & $29 \pm 19$ & $16 \pm 13$ \\
SF & $40 \pm 2$ & $37 \pm 2$ & $3 \pm 1$ & $36 \pm 3$ & $33 \pm 3$ & $31 \pm 3$ & $16 \pm 6$ \\
G & $62 \pm 4$ & $61 \pm 4$ & $21.752 \pm 0$ & $68 \pm 7$ & $66 \pm 7$ & $64 \pm 6$ & $57 \pm 5$ \\
\hline
\end{tabular}

${ }^{1}$ Average \pm standard deviation. 


\subsection{Dyeing Experiment}

The sample plots were selected in the karst fault basin in Jianshui County, Yunnan Province. Sample plots were selected to represent local vegetation types (Pinus Yunnanensis plantation forestland, secondary forestland, and natural grassland) and growth conditions and have relatively consistent site conditions (e.g., elevation, slope position, and slope). Secondary and plantation forests with a stable soil structure and reduced disturbance were selected [33]. The recovery time of the three kinds of woodlands was more than 20 years. A natural secondary forest occurs from secondary bare land through a series of successive stages of the local plant community. And local tree species Pinus Yunnanensis in plantation accounted for a large proportion.

To study the preferential flow characteristics for different stand origins under varied precipitation conditions, we selected flat fields in plantation forestland, secondary forestland, and natural grassland with two replicated transects, under similar environmental characteristics at least three weeks after rainfall to remain dry prior to the dye experiment. Each transect included five vertical sections, and we requested the sample sites to be located at least $10 \mathrm{~m}$ from each other to avoid interferences in the experiments [36]. Before the test, we removed fallen leaves and other coverings from the surface to prevent water from being absorbed by elements other than the soil. At each site, plastic sheets with a length $\times$ width $\times$ height of $0.6 \mathrm{~m} \times 0.6 \mathrm{~m} \times 0.3 \mathrm{~m}$ were used to surround the field. Subsequently, the plastic sheets were embedded $10 \mathrm{~cm}$ into the soil, and the soil around the plastic sheets was uniformly compacted at $5 \mathrm{~cm}$.

As a dye tracer, Brilliant Blue can visually show the distribution of non-uniform flow in soil, that is, preferential flow [16]. Therefore, a $4 \mathrm{~g} / \mathrm{L}$ dye solution was used in 36 tracing experiments [37]. According to rainfall data for the years 2008-2017 in our study area, the distribution of rainfall amounts was: $69 \%$ of the rainfall events for $<10 \mathrm{~mm}$ rain (light rain); $23 \%$ of events for $10-25 \mathrm{~mm}$ (moderate rain); $7 \%$ of events for $25.1-50 \mathrm{~mm}$ rain (heavy rain), and $2 \%$ of events for $>50.1 \mathrm{~mm}$ rain (a storm). In order to simulate and describe water infiltration phenomena under different conditions of surface water accumulation using an in-situ test, we used the one-dimensional ponded water infiltration method to simulate the change of ponded water in four kinds of rainfall conditions, which can reduce water loss and minimize the wastage. Our simulation experiments included rainfall amounts of $5 \mathrm{~mm}$ (a small rainfall event), $15 \mathrm{~mm}$ (median), $35 \mathrm{~mm}$ (large), and $55 \mathrm{~mm}$ (extreme), because the probability of these precipitation events occurring in four kinds of rainfall amounts is higher. The maximum rainfall depth recorded at the study site was $67 \mathrm{~mm}$ during $24 \mathrm{~h}$. Therefore, the applied amounts, especially $35 \mathrm{~mm}$ and $55 \mathrm{~mm}$, should be reasonable. The fields, images and soil samples were numbered G5, G15, G35, and G55, according to the amount of Brilliant Blue solution used. Then, each field was covered with a waterproof cloth that was removed $24 \mathrm{~h}$ after the cessation of infiltration to avoid evaporation of the solution [36]. We removed the waterproof cloth and left a $10 \mathrm{~cm}$ buffer zone at the inner edge of each sheet to prevent the cutting process from affecting the pore structure. The final data were collected in the $50 \mathrm{~cm} \times 50 \mathrm{~cm}$ staining area in the middle of the quadrant, and each quadrant was cut into five vertical sections with $10 \mathrm{~cm}$ spaces between each other. We photographed each vertical section using a digital camera (500D, Canon, Japan) with a $35 \mathrm{~mm}$ focal length. In cases of bright sunlight, we used a parasol to reduce shadow interference [38].

Soil samples were taken at depths of $0-10 \mathrm{~cm}, 10-20 \mathrm{~cm}$, and $20-30 \mathrm{~cm}$. The samples were taken back to the laboratory of graphite digestion instrument to test the chemical properties of soil after digestion with concentrated sulfuric acid and perchloric acid. The samples were assayed by automatic chemical analyzers (the model is Smartchem). Available potassium (AK) used flame photometry method, nitrate nitrogen (NN) used hydrazine sulfate method, total nitrogen (TN) used salicylic acid-hypochlorite spectrophotometry method, available phosphorus (AP) used $\mathrm{NaHCO}_{3}$ method, total phosphorus (TP) used the ammonium molybdate method, organic matter (Org) used potassium dichromate oxidation method. 


\subsection{Image Analysis}

The photos were processed in Photoshop CS3 (Adobe Systems Inc., San Jose, CA, USA) and Image Pro Plus 6.0 (Media Cybernetics Inc., Rockville, MD, USA) to quantify the stained areas [39]. Image analysis geometrically corrected the captured images by using Photoshop CS3. The sizes of the vertical sections of the pictures were cropped to $50 \mathrm{~cm} \times 50 \mathrm{~cm}$ by referring to the image ruler. Then, the saturation, brightness, greyscale, and threshold values were adjusted. The processed images were digitized using Image Pro Plus 6.0, and the pixel of each image was set to $500 \times 500$ to convert the image into binary information, classified into black (pixel value 0 , represents the dye position) and white (pixel value 255, represents the undyed position). We calculated preferential flow indices by using Sigmaplot to calculate these binary matrices (see Figure 1 for visual examples).

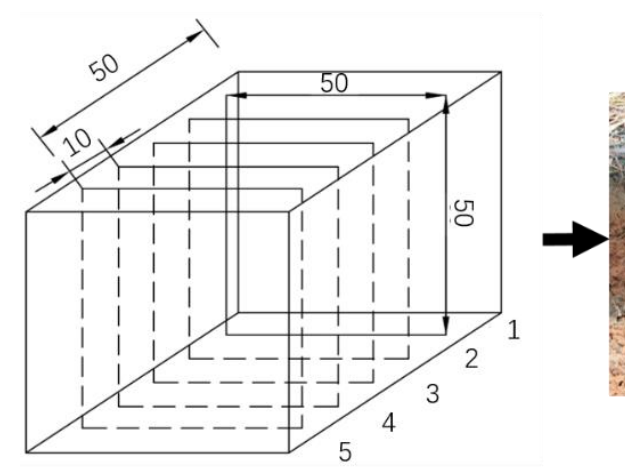

Vertical slices

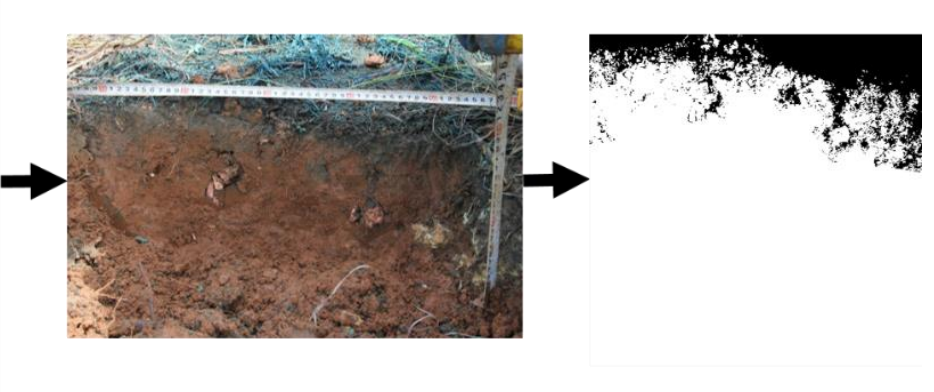

Field slices
After treatment

Figure 1. Example of stained profiles $(\mathrm{cm})$ and image processing.

\subsection{Data Analysis}

Dye coverage $(D C / \%)$ refers to the percentage ratio of the dyed area [40]. The dyeing area ratio is mainly obtained by the ratio of the number of dyed pixels at different depths in each soil layer to the total number of pixels in the image to reflect the degree of preferential flow, which is calculated as:

$$
D C=\frac{D}{D+N D} \times 100 \%
$$

where $D C$ corresponds to $D C(\%), D$ is the stained area of the soil profile $\left(\mathrm{cm}^{2}\right)$ and ND is the unstained area of the soil slices $\left(\mathrm{cm}^{2}\right)$.

Preferential flow fraction $(P F)$ is used to reflect the distribution and degree of preferential flow [41]. A high PF value indicates a high degree of preferential flow [42], which is calculated as:

$$
P F=\left(1-\frac{U F \cdot W}{D T}\right) \cdot 100 \%
$$

where PF is the soil preferential flow fraction (\%); UF is the depth of uniform flow (cm), that is, matrix flow; $W$ is soil profile horizontal width $(\mathrm{cm}) ; D T$ is the total dyed area of the soil sections $\left(\mathrm{cm}^{2}\right)$.

The length index $\left(L_{i}\right)$ of preferential flow has a positive correlation with the degree of heterogeneity of preferential flow [43] and is calculated as:

$$
L_{i}=\sum_{i=1}^{n}\left|D C_{(i+1)}-D C_{i}\right|
$$

where $L_{i}$ is length index of preferential flow (\%), DC $i$ is $D C$ area ratio to the $i$-th layer (\%), and $n$ is the number of pixels in the vertical sections (500 in this study). 
The variation coefficient of the $D C$ in the preferential flow area $\left(C_{V}\right)$ is used to quantitatively describe the change in dyeing morphology after the removal of the matrix flow areas [44] and is calculated as:

$$
C_{V}=\frac{\sqrt{\frac{1}{N-1} \sum_{i=1}^{N}\left(x_{i}-\bar{x}\right)^{2}}}{\frac{1}{N} \sum_{i=1}^{N} x_{i}}
$$

where $C_{V}$ is the variation coefficient of $D C$ in the preferential flow area (-), $N$ is the number of soil sections of preferential flow in vertical sections $(-), \bar{x}$ is the average value of the staining area ratio $(-)$, and $x_{i}$ is the dye area ratio of the soil profile in layer $i$-th (-).

The variation coefficients of the maximum infiltration depths $\left(C_{\mu}\right)$ are used to describe the non-uniform characteristics of the soil water flow in vertical slices [45] and are calculated as:

$$
C_{\mu}=\frac{\sum_{i=1}^{\mathrm{m}}\left|h_{\max }\left(x_{i}, y_{i}\right)-\bar{h}\right|}{m \cdot \bar{h}}
$$

where $C_{\mu}$ is the variation coefficient of maximum infiltration depths $(-), h_{\max }\left(x_{i}, y_{i}\right)$ is the maximum depth of dyeing located at $\left(x_{i}, y_{i}\right)$ of the vertical section $(\mathrm{cm}), \bar{h}$ is the average of all maximum depths $(\mathrm{cm})$, and $\mathrm{m}$ is the number of pixels in the horizontal direction of the vertical section (500 in this study).

\subsection{Structural Equation Model (SEM)}

SEM is widely used due to its empirical analysis capabilities and suitability for latent variable analysis [46]. Compared with traditional statistical methods, SEM introduces latent variables that can simultaneously consider endogenous variables, which can allow errors of measurement in parameter estimation whilst analyzing the direct and indirect effects between variables [47]. The SEM method consists of structural equations and measurement models that are generally represented by three matrix equations, as follows [48].

$$
\eta=B \eta+\Gamma \xi+\zeta,
$$

Equation (6) represents SEM, which reflects the structural relationships between latent variables, which cannot be measured in practice. Where $\eta$ is the endogenous latent variable, $B$ is the correlation coefficient matrix between endogenous latent variables, $\Gamma$ is the structural coefficient matrix of exogenous latent variables on endogenous latent variables, $\xi$ is an exogenous latent variable and $\zeta$ is the measurement error.

$$
\begin{aligned}
Y & =\Lambda_{y} \eta+\varepsilon \\
X & =\Lambda_{x} \xi+\sigma .
\end{aligned}
$$

Equations (7) and (8) represent the measurement models, which can reflect the relationship between observed and latent variables, where $X$ is the exogenous observation variable vector; $Y$ is the endogenous observation variable vector; $\Lambda_{x}$ is the factor loadings of the exogenous observation variable vector; $\Lambda_{y}$ is the factor loadings of endogenous observation variable vector; $\varepsilon$ and $\sigma$ are the measurements of the exogenous and the endogenous observation variables, respectively. Latent variables can be reflected by measurable variables by the use of a measurement model. We can obtain the relationship between each latent variable and measurable variable by solving Equations (6)-(8). After building the initial model, the path coefficients represent the extent of the relationship between the variables. The path coefficients are usually calculated by using the maximum likelihood method. 


\section{Results and Discussion}

\subsection{Spatial Variation of Dyeing Distribution}

Blue Brilliant FCF dye tracer was used to visualize the trace of water at the initial stage of infiltration (24 h), which is a common and effective dyeing reagent [40,49]. We compared and calculated the data extracted from 150 stained vertical sections in three vegetational types, and nine examples are shown in Figure 2. The distribution of dye area was not uniform or similar in the three experimental fields (Figure 2). The uniform infiltration depth $(\mathrm{cm})$, which was calculated as the depth in which $D C$ was $80 \%$ and belongs to the matrix flow, can represent the depth of the uniform infiltration front [43]. In Figure 2, the images in first line are taken from Pinus Yunnanensis forestland fields, the images in second line are taken from secondary forestland fields, and the images in third line are taken from grassland fields; $a, e, i$ correspond to the images under G5 condition; b, $\mathrm{f}, \mathrm{j}$ correspond to the images under G15 condition; c, $g$, k correspond to the images under G35 condition; $d$, h, m correspond to the images under G55 condition. The dyeing area ratio decreased as the soil depth increased [17,39]. The degree of image change indicated the presence of preferential flow in this area and the dominance of matrix flow in the soil slices of grassland. Preferential flow was apparent at Pinus Yunnanensis plantation forestland and secondary forestland, but the spatial distribution of the secondary forestland was noticeably more non-uniform. At the same time, Figure 2, from a to d, e to h, i to m, showed that the infiltration depth increases with the increase of infiltration water volume. We can discuss the characteristic of spatial distribution of preferential flow by drawing the standard deviation images of DC (Figure 3). In general, the standard deviation of DC in Pinus Yunnanensis plantation forestland was more normal and concentrated; the standard deviation of $D C$ in secondary forestland fluctuated significantly; a predominant downward trend in DC in grassland was observed mostly, and where the standard deviation was also the lowest.

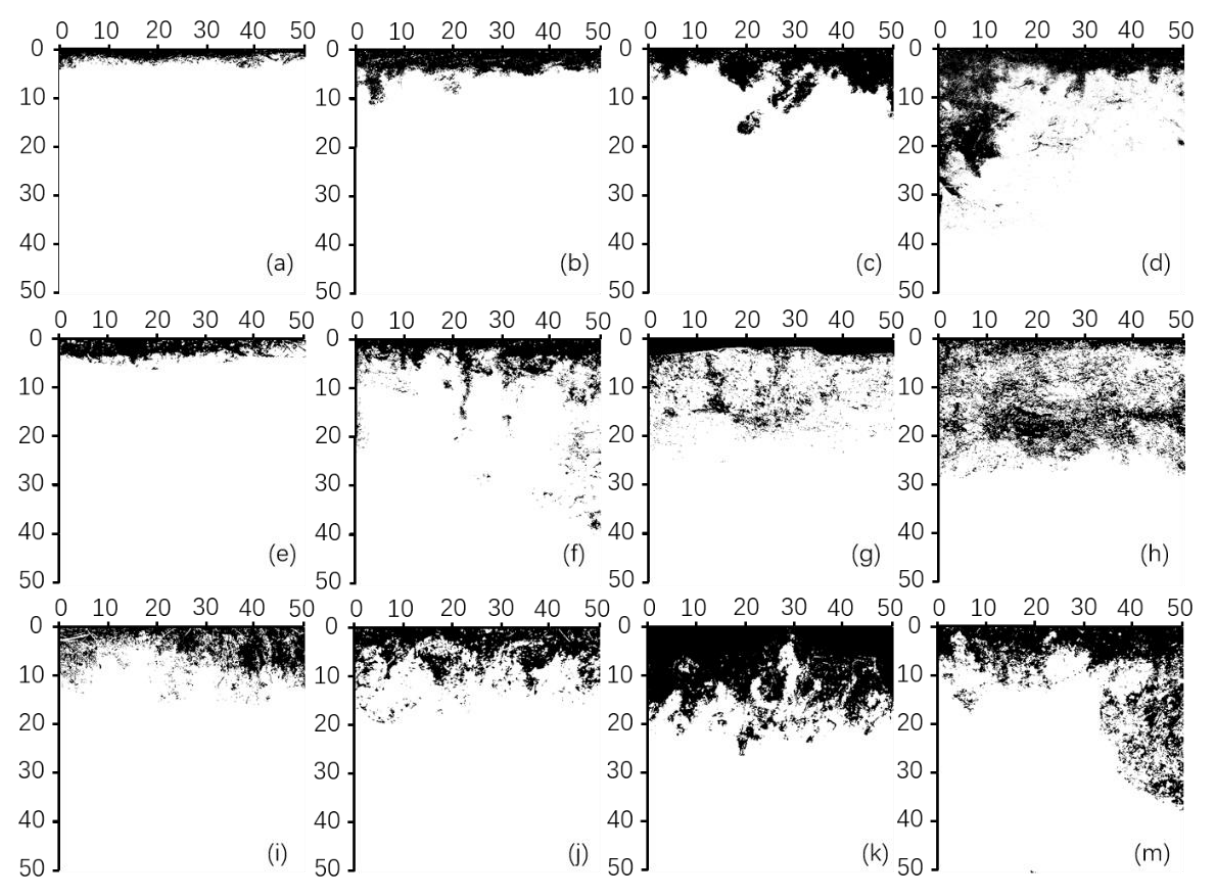

Figure 2. Example dye images for vertical soil sections in the three types of sites under different precipitation amounts. (a-d) correspond to the vertical sections of PY at G5, G15, G35, and G55, respectively; (e-h) refer to the vertical sections of SF at G5, G15, G35, and G55, respectively; (i-m) correspond to the vertical sections of G at G5, G15, G35, and G55, respectively. Among them, G5, G15, G35 and G55 correspond to $5 \mathrm{~mm}, 15 \mathrm{~mm}, 35 \mathrm{~mm}$, and $55 \mathrm{~mm}$ ponded water infiltration simulations, which simulate the change in ponded water in light rain, medium rain, heavy rain, and storm, respectively. 


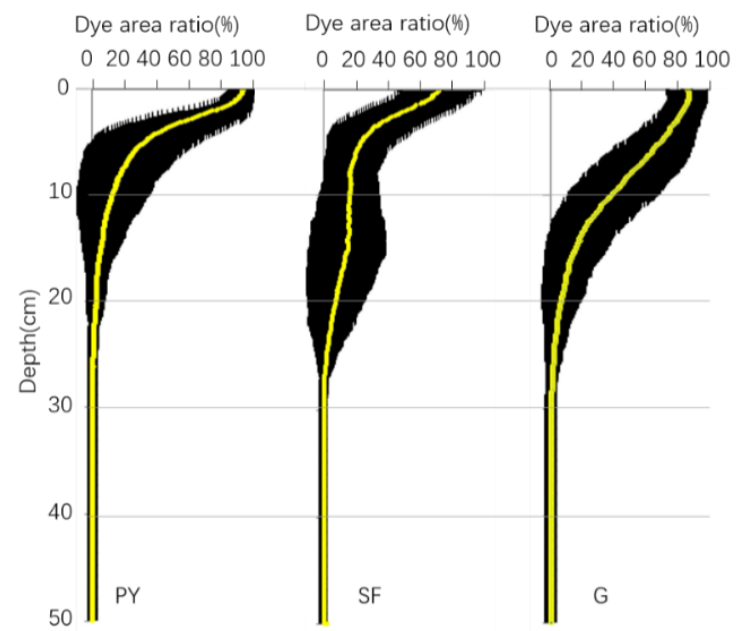

Figure 3. Average dye coverage (DC) (yellow curve) and standard deviation (black part) of three site types. PY corresponds to Pinus Yunnanensis, SF corresponds to secondary forestland, and G corresponds to natural grassland.

We calculated the experimental data using the aforementioned formulas (Table 3). The dyeing area distinctly declined under different conditions. $D C$ rapidly declined in the soil layer from 0 to $5 \mathrm{~cm}$. The dyeing morphological parameters of preferential flow under different infiltration amounts in Table 3 showed that the depth of matrix flow was deepest in grassland, followed by those in Pinus Yunnanensis plantation forestland, and secondary forestland. This phenomenon indicated that the depth of matrix flow may be related to the near-surface vegetational types, water infiltration into the soil through fissures, macropores and pore networks formed by roots, and the higher abundance and uniformity of grass roots in surface soil than in forest land.

However, in the deep soil layer (i.e., $5-15 \mathrm{~cm}$ ), a significant difference was observed in the $D C$ of vertical sections under different field types; these large variations may be related to the pore structure of the soil, that is, the effect of integrated environmental factors, such as soil properties [50]. Table 3 shows that the characteristic parameters of the preferential flow of secondary forestland were bigger than those of Pinus Yunnanensis plantation forestland and grassland. The reason for this was that the soil layer in Pinus Yunnanensis plantation forestland is thicker than in secondary forestland, but the main preferential flow path is the root system of trees, which influences the connectivity of macropores; thus, the standard deviation of Pinus Yunnanensis plantation forestland is higher than that of grassland, and this finding is consistent with that of Alaoui et al. [37]. For the same reason, the forestland macropores can efficiently transport vertically downwards compared to those of the grassland soil. This phenomenon is important in soil hydrological processes (e.g., the soil water cycle and water infiltration rate). The preferential flow pathway of secondary forestland is extremely developed because of the following: (1) the special morphology and high heterogeneity of the soil structure in karst regions [35], (2) the fact that the fracture between rock and soil has become a preferential pathway for transporting surface water to deep soil layers [51], and (3) the non-uniform distribution of fissures in surface soil, which is caused by the lack of uniform vegetation cover. 
Table 3. Characteristic parameters of preferential flow variables.

\begin{tabular}{|c|c|c|c|c|c|c|c|c|c|}
\hline \multicolumn{3}{|c|}{ Treatment } & \multirow{2}{*}{$U F^{1} / \mathrm{cm}$} & \multirow{2}{*}{$I D^{2} / \mathrm{cm}$} & \multirow{2}{*}{$D C^{3} / \%$} & \multirow{2}{*}{$P F^{4} / \%$} & \multirow{2}{*}{$L_{i}{ }^{5} / \%$} & \multirow{2}{*}{$C_{V}{ }^{6}$} & \multirow{2}{*}{$C_{\mu}{ }^{7}$} \\
\hline Site Type & Waterhead Hight/cm & Sample Number & & & & & & & \\
\hline \multirow{10}{*}{ PY } & \multirow{3}{*}{3.6} & 1 & $1.56 \pm 1.43$ & $5.20 \pm 1.29$ & $4.22 \pm 0.66$ & $0.92 \pm 0.08$ & \multirow{3}{*}{$13.52 \pm 4.46$} & \multirow{3}{*}{$0.30 \pm 0.09$} & \multirow{3}{*}{$0.0032 \pm 0.0016$} \\
\hline & & 2 & $1.38 \pm 0.76$ & $7.60 \pm 1.49$ & $6.12 \pm 2.10$ & $0.96 \pm 0.01$ & & & \\
\hline & & 3 & $1.02 \pm 0.50$ & $10.18 \pm 6.04$ & $6.08 \pm 1.82$ & $0.96 \pm 0.02$ & & & \\
\hline & \multirow{3}{*}{10} & 1 & $2.50 \pm 1.78$ & $14.02 \pm 7.41$ & $9.22 \pm 4.70$ & $0.95 \pm 0.02$ & \multirow{3}{*}{$33.50 \pm 7.59$} & \multirow{3}{*}{$0.45 \pm 0.09$} & \multirow{3}{*}{$0.0030 \pm 0.0011$} \\
\hline & & 2 & $3.60 \pm 0.74$ & $16.18 \pm 3.87$ & $12.91 \pm 4.13$ & $0.94 \pm 0.01$ & & & \\
\hline & & 3 & $3.42 \pm 2.77$ & $13.82 \pm 4.59$ & $11.94 \pm 4.54$ & $0.95 \pm 0.04$ & & & \\
\hline & \multirow{2}{*}{25} & 1 & $1.32 \pm 1.22$ & $9.22 \pm 2.73$ & $7.07 \pm 2.29$ & $0.97 \pm 0.03$ & \multirow{2}{*}{$19.17 \pm 5.69$} & \multirow{2}{*}{$0.34 \pm 0.02$} & \multirow{2}{*}{$0.0018 \pm 0.0003$} \\
\hline & & 2 & $1.82 \pm 0.99$ & $14.34 \pm 2.41$ & $10.15 \pm 2.95$ & $0.97 \pm 0.02$ & & & \\
\hline & \multirow{2}{*}{40} & 1 & $2.66 \pm 3.77$ & $25.26 \pm 4.26$ & $14.84 \pm 8.45$ & $0.98 \pm 0.03$ & \multirow{2}{*}{$29.48 \pm 1.74$} & \multirow{2}{*}{$0.58 \pm 0.05$} & \multirow{2}{*}{$0.1376 \pm 0.1363$} \\
\hline & & 2 & $3.58 \pm 3.81$ & $22.58 \pm 8.29$ & $15.77 \pm 7.50$ & $0.96 \pm 0.03$ & & & \\
\hline \multirow{8}{*}{ SF } & \multirow{2}{*}{3.6} & 1 & $0.12 \pm 0.04$ & $5.10 \pm 0.66$ & $2.94 \pm 1.30$ & $0.99 \pm 0.00$ & \multirow[b]{2}{*}{$5.31 \pm 2.16$} & \multirow[b]{2}{*}{$0.41 \pm 0.09$} & \multirow[b]{2}{*}{$0.0020 \pm 0.0012$} \\
\hline & & 2 & $0.10 \pm 0.06$ & $7.26 \pm 2.68$ & $2.19 \pm 0.62$ & $0.99 \pm 0.00$ & & & \\
\hline & \multirow[b]{2}{*}{10} & 1 & $2.08 \pm 1.13$ & $22.78 \pm 8.97$ & $10.17 \pm 1.98$ & $0.96 \pm 0.01$ & \multirow{2}{*}{$17.65 \pm 4.51$} & \multirow{2}{*}{$0.42 \pm 0.21$} & \multirow{2}{*}{$0.0028 \pm 0.0002$} \\
\hline & & 2 & $0.10 \pm 0.06$ & $11.72 \pm 3.29$ & $3.77 \pm 2.12$ & $0.99 \pm 0.01$ & & & \\
\hline & & 1 & $0.40 \pm 0.60$ & $17.34 \pm 2.65$ & $9.16 \pm 3.52$ & $0.99 \pm 0.01$ & & & \\
\hline & 25 & 2 & $0.12 \pm 0.04$ & $16.7 \pm 1.95$ & $10.33 \pm 2.92$ & $1.00 \pm 0.00$ & $26.42 \pm 0.59$ & $0.37 \pm 0.06$ & $0.0012 \pm 0.0001$ \\
\hline & 40 & 1 & $0.56 \pm 0.74$ & $25.94 \pm 3.52$ & $18.39 \pm 3.41$ & $0.99 \pm 0.01$ & & & \\
\hline & 40 & 2 & $0.40 \pm 0.28$ & $25.40 \pm 3.30$ & $19.48 \pm 3.86$ & $1.00 \pm 0.00$ & .46 & \pm 0.01 & $0.0010 \pm 0.0001$ \\
\hline
\end{tabular}


Table 3. Cont.

\begin{tabular}{|c|c|c|c|c|c|c|c|c|c|}
\hline \multicolumn{3}{|c|}{ Treatment } & \multirow{2}{*}{$U F^{1} / \mathrm{cm}$} & \multirow{2}{*}{$I D^{2} / \mathrm{cm}$} & \multirow{2}{*}{$D C^{3} / \%$} & \multirow{2}{*}{$P F^{4} / \%$} & \multirow{2}{*}{$L_{i}{ }^{5} / \%$} & \multirow{2}{*}{$C_{V}{ }^{6}$} & \multirow{2}{*}{$C_{\mu}{ }^{7}$} \\
\hline Site Type & Waterhead Hight $/ \mathrm{cm}$ & Sample Number & & & & & & & \\
\hline \multirow{12}{*}{ G } & & 1 & $0.88 \pm 0.65$ & $12.64 \pm 1.63$ & $8.97 \pm 2.12$ & $0.98 \pm 0.01$ & & & \\
\hline & 3.6 & 2 & $1.12 \pm 0.98$ & $13.20 \pm 2.14$ & $8.57 \pm 1.05$ & $0.97 \pm 0.02$ & $23.05 \pm 11.20$ & $0.22 \pm 0.06$ & $0.0014 \pm 0.0003$ \\
\hline & & 3 & $2.98 \pm 2.37$ & $19.46 \pm 3.73$ & $14.53 \pm 3.29$ & $0.96 \pm 0.03$ & & & \\
\hline & & 1 & $2.22 \pm 2.29$ & $16.52 \pm 1.21$ & $17.35 \pm 2.27$ & $0.97 \pm 0.02$ & & & \\
\hline & 10 & 2 & $0.98 \pm 1.12$ & $15.70 \pm 2.71$ & $11.66 \pm 2.63$ & $0.98 \pm 0.02$ & $26.16 \pm 3.49$ & $0.20 \pm 0.04$ & $0.0009 \pm 0.0003$ \\
\hline & & 3 & $0.74 \pm 1.23$ & $16.82 \pm 1.49$ & $12.54 \pm 2.29$ & $0.99 \pm 0.02$ & & & \\
\hline & & 1 & $5.28 \pm 1.67$ & $22.08 \pm 1.48$ & $19.81 \pm 2.57$ & $0.95 \pm 0.01$ & & & \\
\hline & 25 & 2 & $6.72 \pm 1.27$ & $22.46 \pm 2.76$ & $23.74 \pm 3.30$ & $0.94 \pm 0.01$ & $35.19 \pm 7.41$ & $0.19 \pm 0.04$ & $0.0008 \pm 0.0002$ \\
\hline & & 3 & $3.96 \pm 2.34$ & $19.36 \pm 1.61$ & $17.67 \pm 3.72$ & $0.96 \pm 0.02$ & & & \\
\hline & & 1 & $3.26 \pm 2.07$ & $29.44 \pm 2.40$ & $26.03 \pm 4.08$ & $0.98 \pm 0.01$ & & & \\
\hline & 40 & 2 & $0.56 \pm 0.63$ & $24.40 \pm 1.84$ & $21.46 \pm 2.11$ & $1.00 \pm 0.01$ & $44.39 \pm 6.20$ & $0.16 \pm 0.03$ & $0.0007 \pm 0.0001$ \\
\hline & & 3 & $6.66 \pm 3.85$ & $27.84 \pm 2.13$ & $29.15 \pm 4.99$ & $0.96 \pm 0.02$ & & & \\
\hline
\end{tabular}

${ }^{1} \mathrm{UF}$ correspond to depth of uniform flow (matrix flow). ${ }^{2} \mathrm{ID}$ corresponds to infiltration depth. ${ }^{3} \mathrm{DC}$ correspond to dye coverage. ${ }^{4} \mathrm{PF}$ correspond to the preferential flow fraction. ${ }^{5} \mathrm{~L}_{i}$ corresponds to length index of preferential flow. ${ }^{6} C_{V}$ correspond to variation coefficient of dye coverage in preferential flow area. ${ }^{7} C_{\mu}$ corresponds to variation coefficients of maximum infiltration depths. 
The characteristic parameters of the preferential flow (e.g., ID (infiltration depth), UF, DC, $P F$, and $L_{i}$ ) can be calculated using the image data of stained vertical profiles, which can quantitatively evaluate the characteristics of dyeing morphology and the differences under various infiltration conditions and reveal the non-uniform characteristics of preferential flow under different infiltration conditions in karst regions (Table 3). The characteristic parameters under different vegetational types vary. Most indicators showed that $\mathrm{G}>\mathrm{PY}>\mathrm{SF}$ regardless of infiltration conditions, such as UF, DC and $L_{i}$. However, exceptions were observed, such as ID and PF. The UF values of Pinus Yunnanensis plantation forestland, secondary forestland, and grassland were $17 \%, 3 \%$, and $14 \%$ of $I D$, respectively, indicating that the infiltration depth can be affected by the types of vegetation on the surface when using the same infiltration amount. The $C_{V}$ and $C_{\mu}$ of Pinus Yunnanensis plantation forestland were larger than those of secondary forestland and grassland. The surface coverage of grassland was nearly $100 \%$; grassland can preserve moisture in an environment with a very large differences in the humidity values, such as in Yunnan, due to the shallow root systems. However, water infiltration in forestland, such as Pinus Yunnanensis plantation forestland and secondary forestland, is largely dependent on the root system and fractures, such as the crevices between rocks and soil, which can preferentially transport water to deep soil layers. Thus, preferential flow in forestlands is highly developed. The standard deviations of UF under G55 and ID under G15 and G55 are large, indicating that the process of water flow, including non-uniform flow, can confirm the presence of preferential flow [39]. Relative to non-karst regions, ID is extremely deep. The reason may be due to the unique dual structure of karst landform (soil-rock) [51]. Preferential flow becomes the major form of soil moisture transport in this area due to high heterogeneity and fissure structure. $L_{i}$ can also reflect the difference between preferential and matrix flows [52]. Although $P F$ and $L_{i}$ are parameters used for measuring preferential flow, the former emphasizes the dyeing region in the whole stained vertical section and the other focuses on different soil layers.

Figure 4 is based on the average DC of Pinus Yunnanensis plantation forestland, secondary forestland, and grassland after treatment with different infiltration amounts. It is evident that there is a downward trend in the average DC. Regardless of the infiltration changes amongst G5, G15, and G35, the regular infiltration of $D C$ was similar and uniform, thereby indicating that the soil has a good water storage capacity. However, the fluctuation of forestland in storm conditions (G55) was conspicuous. The changing trend of grassland was similar to those in other infiltration treatments, but the fluctuation of Pinus Yunnanensis plantation forestland was less than that of secondary forestland, which meant that Pinus Yunnanensis plantation forestland can buffer vertical water infiltration better than the secondary forestland. Table 3 shows that the characteristic parameters of stained vertical sections increased with the amount of infiltration. The UF of G35 was similar to that of G55, which was almost twice those of both G5 and G15. The ID of G35 was similar to that of G15, but the ID of G55 was 1.60 times higher than that of G35, and those of G15 and G35 were 2.65 times higher than that of G5. The DC of G55 was significantly higher than those of the other infiltration conditions, which were 3.19, 1.86, and 1.54 times those of G5, G15, and G35, respectively. The PF under the four infiltration conditions was similar but still followed the rule of G5 (97\%) < G15 (97\%) < G35 (97\%) < G55 (98\%), and PY < SF < G, which meant that preferential flow can occupy a large proportion during water infiltration and occupy a small proportion in Pinus Yunnanensis plantation forestland incidents with less ponded water (G5). The $L_{i}$ of G55 was 2.40 times that of G5 and 1.30 times those of G15 and G35. The $C_{V}$ was similar under the four infiltration conditions, but that of G15 was significantly larger than the others. The $C_{\mu}$ of G55 was 21 times those in the other three conditions, indicating that, among the extreme events, large water accumulation will affect the variability of the maximum water infiltration depth. The increase in infiltration amounts thus had a certain promoting effect on UF and ID. Moreover, the UF of G5, G15, G35 and G55 were 34\%, 33\%, 39\% and 28\% of ID, respectively, indicating that, in typical ponded water events, an increase in infiltration water has a certain promoting effect on the depth of matrix flow and its proportion. When the extreme events of large water accumulation occur, preferential flow dominates the process of water infiltration due to the special soil structure of karst landforms. This 
group of data demonstrated that the matrix flow under the different infiltration conditions showed no remarkable variation. $L_{i}$ increased with precipitation, and G55 was significantly larger than G35 and G15. G5 was significantly smaller than the three other infiltration conditions. Most parameters under G55 and its standard deviations were far greater than those in the three other infiltration conditions, indicating that water infiltration (e.g., preferential flow) will remarkably fluctuate during large ponded water events. Thus, we need to investigate the process of preferential flow under different conditions, its influencing factors and its impact on the environment.
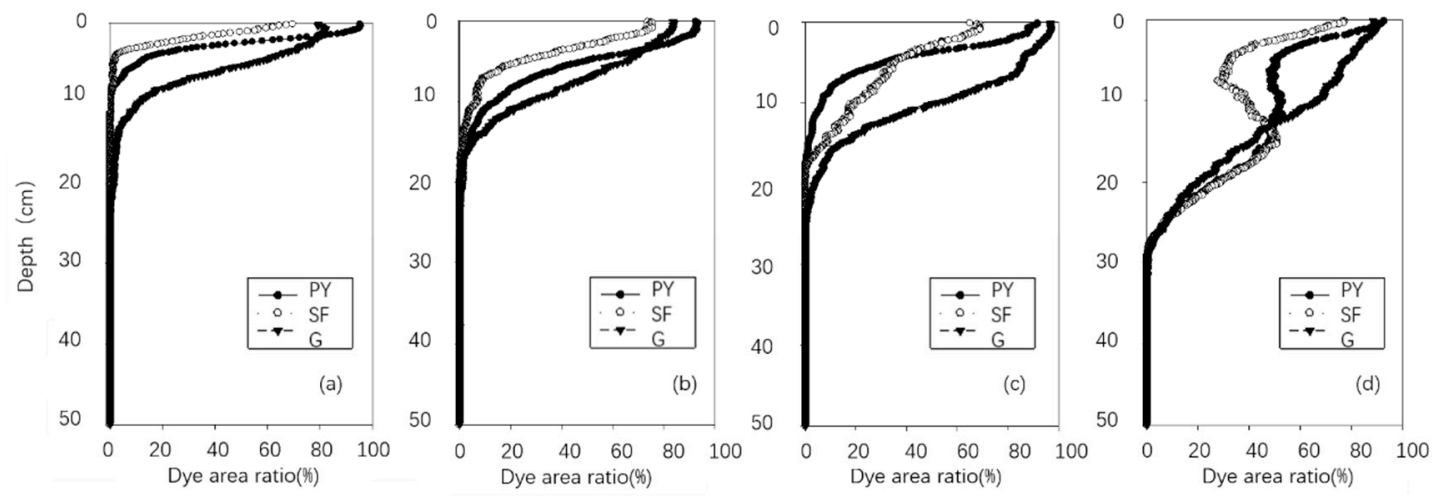

Figure 4. Average DC curve under different precipitation amounts ((a) is G5, (b) is G15, (c) is G35, (d) is G55). PY corresponds to Pinus Yunnanensis forestland, SF corresponds to secondary forestland, and G corresponds to natural grassland. Among them, G5, G15, G35, and G55 correspond to $5 \mathrm{~mm}, 15 \mathrm{~mm}$, $35 \mathrm{~mm}$, and $55 \mathrm{~mm}$ ponded water infiltration simulation, which simulate the change of ponded water in light rain, medium rain, heavy rain, and storm, respectively.

The changes in $C_{V}$ and $C_{\mu}$ can reveal the permeation mode of spatial variability in karst regions [53]. $C_{V}$ does not decrease with the increase in the infiltration amount (Table 3). This finding conflicts with the results of Yao et al. (2018) [39]. The reason may be due to the different spatial heterogeneities of soil in karst regions, which can strongly affect the depth of soil moisture and the development of preferential flow. As shown in Table 3, $C_{\mu}$ was negatively correlated with the amount of infiltration, and the water volume had a remarkable influence on the non-uniformity of the maximum infiltration depth. The $C_{\mu}$ of Pinus Yunnanensis plantation forestland was significantly greater than those in secondary forestland and natural grassland, indicating that the depth of infiltration had a strong spatial dependence in each forestland. This phenomenon illustrated substantial water translocation between the preferential flow path and the surrounding soil matrix. Transferring soil moisture to compacted soil or rock is more difficult than from the soil matrix to the surrounding environment [54]. However, cracks caused by rocks or roots can enhance the development of preferential flow and increase the spatial variation in the morphological characteristics of the infiltration. Therefore, artificial land preparation and the rational allocation of surface vegetation can change the spatial heterogeneity of vertical preferential infiltration, and these results are consistent with those of Shinohara and Otsuki [55]. The spatial variation $\left(C_{V}\right.$ and $C_{\mu}$ ) of Pinus Yunnanensis plantation forestland was greater than that of secondary forestland, and grassland was the smallest, indicating that artificial land preparation and rational allocation of surface vegetation can increase the variability of the water infiltration process.

\subsection{Relationship between Preferential Flow and Infiltration}

Different from loess plateaus [36] and wetlands [56], for which pollutant diffusion models have been established, karst areas require further research. Thus, we need to study the relationship between surface water infiltration caused by ponded water and preferential flow. Many latent variables cannot be directly observed during the infiltration process because of the imperceptibility of soil, and these latent variables cause errors. SEM has been shown to be verifiable [48]. To accurately study preferential flow, we need to consider not only the correlation between variables but also the errors. Hence, we 
designed a relationship model between latent variables and estimated the fit of the initial model with the measured data. This study used SEM to construct and evaluate the index system, which can reflect the interrelationship between latent variables (exogenous and endogenous latent variables) [48]. In this study, we used the software Amos 7.0 (Analysis of Moment Structures, developed by James L. Arbuckle. Amos 7.0 is a plugin for SPSS.) to construct the SEM equation.

The difference between the correlation coefficient calculated by SEM and the Pearson correlation coefficient is that Pearson will assume no limit due to measurement error, but SEM can provide not only an overall model test but also an independent parameter estimation test, thereby reducing the errors. Thus, the interference in correlation estimates between latent variables caused by measurement errors can be reduced. This method can explain the measurement errors. According to the multivariate statistics of James Stevens' social science application, at least 15 samples per factor are observed in the standard multiple regression analysis. We had 150 samples of vertical sections; therefore, this method was appropriate.

Initially, we measured the reliability of all the data with split-half reliability to display the Cronbach's alpha coefficient of each characteristic parameter. The Cronbach's alpha was calculated by SPSS (Statistical Product and Service Solutions, developed by IBM) as 0.72 , which is greater than 0.70 , indicating good data reliability. The path diagram of SEM was established after several revisions (Figure 5). Tables 4 and 5 show the path coefficients, standard errors, critical ratios, and significance of the influencing factor of the model between each characteristic parameter of preferential flow [46], Table 6 show the evaluation and fitting results of overall SEM fitness. We used maximum likelihood to perform simulation operations and corrected the model according to critical ration (CR); the path coefficient is significantly different from 0 at $95 \%$ confidence when $C R>2$. The CR of each observed variable was greater than 2 , indicating that we can use this model to study the correlation of preferential flow characteristic parameters.

In this study, the absolute fit index and the relative fit index were used to test the model (Table 5). Each of them conformed to the standard, indicating that the available of the model. Figure 5 and Tables 4 and 5 show that $U F$ was significantly negatively correlated with $P F$ (standardized estimate is $-0.95)$, and $D C$ was significantly positively correlated with $L_{i}$ (standardized estimate is 0.73 ). $P F$ was calculated by UF (Equation (2)). Thus, the correlation coefficient between these parameters was the largest. The increment in $U F$ also increased $D C$, and $D C$ would promote $L_{i}$, which indicated that the increase in matrix flow would not only inhibit the development of preferential flow but also increase the difference between the matrix and preferential flows. Ponded water was significantly positively correlated with $I D$ (standardized estimate is 0.68 ) and $D C$ (standardized estimate is 0.62 ), indicating that water infiltration caused by ponded water promoted increases in $D C$ and $I D$, that is, the development degree of preferential flow. Our results are consistent with those of Yao et al. (2017) [39]. When the pore structure of soil remains unchanged, $D C$ will increase with the infiltration amount, and the increasing $D C$ will increase $L_{i} . C_{V}$ will decrease as $L_{i}$ increases because of the significant negative correlation between $C_{V}$ and $L_{i}$. Thus, the increase in the amount of ponded water may decrease $C_{V}$. Dyeing morphology is more standardized if $L_{i}$ is large, and the vertical migration of water is more significant than other forms of migration. Table 6 shows that the results in Tables 4 and 5 are credible, the results of SEM is feasible, because the statistical test quantity of the model conform the standards. Therefore, a large amount of infiltration will reach deep soil rather than remain in shallow soil. 


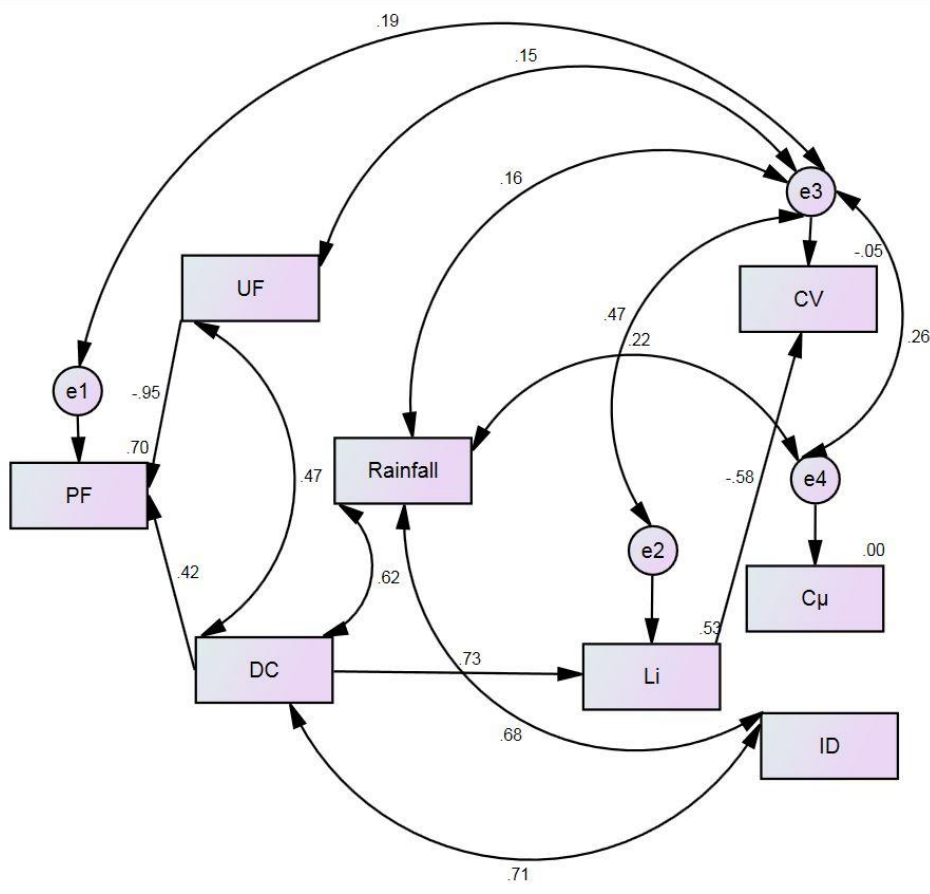

Figure 5. SEM of preferential flow characteristic parameters (e represents the errors).

Table 4. Regression results of SEM variables.

\begin{tabular}{cccccccc}
\hline Path & & $\begin{array}{c}\text { Non-Standardized } \\
\text { Estimate }\end{array}$ & S.E. & CR $^{2}$ & $\mathbf{P}^{3}$ & $\begin{array}{c}\text { Standardized Path } \\
\text { Coefficient Estimation }\end{array}$ \\
\hline$L_{i}$ & $<-$ & $D C$ & 1.15 & 0.08 & 14.18 & $* * * 4$ & 0.73 \\
$P F$ & $<-$ & $D C$ & 0.00 & 0.00 & 8.03 & $* * *$ & 0.42 \\
$C_{V}$ & $<-$ & $L_{i}$ & -0.00 & 0.00 & -5.69 & $* * *$ & -0.58 \\
$P F$ & $<-$ & $U F$ & -0.01 & 0.00 & -16.37 & $* * *$ & -0.95 \\
\hline
\end{tabular}

${ }^{1}$ S.E. corresponds to the smallest eigenvalue. ${ }^{2} \mathrm{CR}$ corresponds to critical ration. ${ }^{3} \mathrm{P}$ corresponds to the probability of obtaining the critical ratio in absolute value. ${ }^{4 * * *}$ corresponds to the probability of obtaining the critical ratio in absolute value is less than 0.001 . In other words, the regression weight is significantly different from zero at the 0.001 level (two-tailed).

Table 5. Covariances results of SEM variables.

\begin{tabular}{cccccccc}
\hline & Path & & $\begin{array}{c}\text { Non-Standardized } \\
\text { Estimate }\end{array}$ & S.E. & CR & P & $\begin{array}{c}\text { Standardized Path } \\
\text { Coefficient Estimation }\end{array}$ \\
\hline$D C$ & $<->$ & $U F$ & 8.21 & 1.21 & 6.77 & $* * *$ & 0.47 \\
$D C$ & $<->$ & $R_{f}{ }^{1}$ & 81.42 & 11.48 & 7.09 & $* * *$ & 0.62 \\
$D C$ & $<->$ & $I D$ & 37.88 & 5.02 & 7.55 & $* * *$ & 0.71 \\
$R_{f}$ & $<->$ & $I D$ & 97.78 & 14.06 & 6.96 & $* * *$ & 0.68 \\
$\mathrm{e} 3$ & $<->$ & $\mathrm{e} 2$ & 0.53 & 0.12 & 4.39 & $* * *$ & 0.47 \\
$\mathrm{e} 4$ & $<->$ & $R_{f}$ & 0.20 & 0.06 & 3.72 & $* * *$ & 0.22 \\
$\mathrm{e} 3$ & $<->$ & $\mathrm{e} 4$ & 0.00 & 0.00 & 3.60 & $* * *$ & 0.26 \\
\hline
\end{tabular}

${ }^{1} R_{f}$ corresponds to the simulated amount of ponded water infiltration. 
Table 6. Evaluation and fitting results of SEM overall fitness.

\begin{tabular}{ccccc}
\hline \multicolumn{2}{c}{ Statistical Test Quantity } & Actual Fitting & Standard & Results \\
\hline \multirow{3}{*}{ Absolute fit index } & $\mathrm{x}^{2} / \mathrm{df}^{1}$ & 2.54 & $<5$ & Conforms \\
& GFI $^{2}$ & 0.94 & $>0.90$ & Conforms \\
& RMSEA $^{3}$ & 0.10 & $<0.10$ & Approximate \\
\hline \multirow{3}{*}{ Relative fitting index } & $\mathrm{NFI}^{4}$ & 0.95 & $>0.90$ & Conforms \\
& $\mathrm{TLI}^{5}$ & 0.94 & $>0.90$ & Conforms \\
& $\mathrm{CFI}^{6}$ & 0.97 & $>0.90$ & Conforms \\
\hline
\end{tabular}

${ }^{1} \mathrm{x}^{2} / \mathrm{df}$ corresponds to the ratio of chi-square and freedom. ${ }^{2}$ GFI corresponds to the goodness of fit index. ${ }^{3}$ RMSEA corresponds to the root meant square error of approximation. ${ }^{4}$ NFI corresponds to the normative fit index. ${ }^{5}$ TLI corresponds to Tucker-Lewis index. ${ }^{6} \mathrm{CFI}$ is the comparative fit index.

\subsection{Relationship between Preferential Flow and Soil Nutrients}

The occurrence and development of preferential flow in the soil are closely related to water, transport, and the accumulation of nutrients in the soil $[57,58]$. In this study, we used SPSS to calculate the soil nutrients and characteristic parameters of preferential flow to study the correlation between preferential flow and the accumulation of soil nutrients (Table 7). Some of the measured nutrients showed large heterogeneity between fields [23], such as AK, AP and Org. However, the correlation between TP, TN, NN, and preferential flow is low, which may be due to the relative stability of TN, TP, and NN; the accumulation of these nutrients may be related to the biomass of surface vegetation [1]. However, available nutrients are more easily absorbed by plants, and because of strong solubility of available nutrients [59], we should pay attention to the correlation between preferential flow and available nutrients. The correlations amongst $\mathrm{AK}$ and $I D, D C$ and $L_{i}$ were positive, and the correlations between $\mathrm{AK}$ and $C_{V}$ and $C_{\mu}$ were negative. The correlations between $\mathrm{AP}$ and $U F$ and $D C$ were positive, and the correlations between $\mathrm{AP}$ and $C_{V}$ and $C_{\mu}$ were negative. The correlations between Org and $P F$ and $C_{V}$ were positive, and the correlations between Org and $U F$ was negative. Therefore, the preferential flow is closely related to the transport and distribution of important nutrients. The relationship between preferential flow and nutrient accumulation and distribution requires further study. This experiment cannot be processed by SEM due to the limitations in the sample size. Thus, the correlation coefficient calculated by SPSS is also reliable.

Table 7 indicates that the accumulation of available nutrients increases with $D C$ and decreases with the increase of $C_{V}$ and $C_{\mu}$. The correlation between the distribution of AP and DC is evidently strong. This indicates that preferential flow can transport AP to deeper soil and is consistent with Julich et al. [60]. By combining the results detailed in Table 7 and the analysis in Section 3.1, DC of grassland is higher than the Pinus Yunnanensis plantation forestland and secondary forestland, and $C_{V}$ and $C_{\mu}$ are lower than Pinus Yunnanensis plantation forestland and secondary forestland, which indicates that the increase of preferential flow variability in grasslands may delay the accumulation of available nutrients. The accumulation of organic matters increases with $P F$ and $C_{V}$ and decreases with the increase of $U F$. By combining the results detailed in Table 7 and the analysis in Section 3.1, UF of secondary forestland is lower than Pinus Yunnanensis plantation forestland and grassland, PF of secondary forestland is the highest, and $C_{V}$ of Pinus Yunnanensis plantation forestland is also the highest, which indicates that natural forestland contained more Org. However, $C_{V}$ is strongly correlated with available nutrients (negative correlation) and Org (positive correlation), and $C_{V}$ of Pinus Yunnanensis plantation forestland is higher than secondary forestland and grassland. Thus, the preferential flow of plantation forestland may promote the accumulation of organic matters. The accumulation of organic matter in karst should be studied because organic matters can improve the physical properties and softness of soil. Table 7 shows that the variability of preferential flow in the plantation can promote the accumulation of organic matters.

$C_{V}$ decreases with the increase of infiltration, according to the conclusions of Section 3.2. Thus, the increase in the infiltration leads to the loss of organic matter. Owing to the special geological 
conditions, soil formation speed is slow and the underground connectivity is high, thereby developing preferential flow. However, the risk that nutrients in the soil enter underground with preferential flow before being absorbed and utilized in the growth of surface plants is high due to the frequent rainfall in karst areas. Therefore, studies on soil erosion under karst landforms should be carried out, not only to include hydraulic erosion but also soil nutrient loss.

Plantation forestland is actively being planned to control rocky desertification in karst areas. The rational allocation of vegetation restoration should be considered for the sustainable development of planted forests. The soil can provide enough nutrients and water resources for afforestation by improving the accumulation of available nutrients and water conservation. The results showed that the accumulation of available nutrients in shallow soil could be promoted by increasing the planting of near-surface vegetation (herbaceous plants). It can also promote the accumulation of organic matter by reducing $U F$ or increasing $P F$ and $C_{V}$. The contribution of preferential flow to groundwater and solute transport needs to be studied under more kinds of vegetation types because of the limitations in the limited sample size at the present. In future studies on karst land degradation, preferential flow needs to be considered and researched thoroughly.

Table 7. Correlation analysis between cumulative content of nutrients in soil and the characteristic parameters of preferential flow.

\begin{tabular}{cccccccc}
\hline Element Name & UF & ID & DC & $P F$ & $L_{i}$ & $C_{V}$ & $C_{\mu}$ \\
\hline $\mathrm{AK}^{1}$ & $0.69^{* 7}$ & $0.86^{* * 8}$ & $0.81^{* *}$ & -0.23 & $0.82^{* *}$ & $-0.81^{* *}$ & $-0.90^{* *}$ \\
$\mathrm{NN}^{2}$ & -0.26 & -0.18 & -0.28 & 0.06 & -0.15 & 0.05 & 0.14 \\
$\mathrm{TN}^{3}$ & -0.22 & 0.46 & 0.11 & 0.61 & 0.56 & 0.16 & -0.42 \\
$\mathrm{AP}^{4}$ & $0.83^{* *}$ & $0.74^{*}$ & $0.85^{* *}$ & -0.44 & $0.73^{*}$ & $-0.89^{* *}$ & $-0.85^{* *}$ \\
$\mathrm{TP}^{5}$ & -0.31 & 0.41 & -0.07 & $0.68^{*}$ & 0.59 & 0.30 & -0.40 \\
$\mathrm{Org}^{6}$ & $-0.84^{* *}$ & -0.19 & $-0.68^{*}$ & $0.87^{* *}$ & 0.06 & $0.82^{* *}$ & 0.18 \\
\hline
\end{tabular}

${ }^{1} \mathrm{AK}$ corresponds to available potassium $/ \mathrm{ug} \cdot \mathrm{mL}^{-1} \cdot{ }^{2} \mathrm{NN}$ corresponds to nitrate nitrogen $/ \mathrm{mg} \cdot \mathrm{kg}^{-1} \cdot{ }^{3} \mathrm{TN}$ corresponds to total nitrogen $/ \mathrm{g} \cdot \mathrm{kg}^{-1} .{ }^{4} \mathrm{AP}$ corresponds to available phosphorus $/ \mathrm{mg} \cdot \mathrm{kg}^{-1}$. ${ }^{5} \mathrm{TP}$ corresponds to total phosphorus $/ \mathrm{g} \cdot \mathrm{kg}^{-1}$. ${ }^{6}$ Org corresponds to organic matter/\%. ${ }^{7 *}$ correlation is significant at a 0.05 level (two-tailed). ${ }^{8 * *}$ correlation is significant at a 0.01 level (two-tailed).

\section{Conclusions}

Preferential flow can quickly transport surface water to deep soil. Because of the high surface temperature and evaporation in this area, preferential flow reduces surface water retention and increases available water for underground root growth. The preferential flow characteristics and accumulative distribution of nutrients in Pinus Yunnanensis plantation forestland, secondary forestland, and grassland fields were investigated using dye tracer experiments, which can reveal water infiltration patterns. This study reflects the response of preferential flow to the amount of infiltration (and some nutrients) under different water infiltration conditions. The precipitation amounts of nutrients can be significantly affected by the preferential flow in karst areas. Moreover, preferential flow can be effectively studied by SEM. The variation in preferential flow with depth results in spatial variability, which is influenced by the characteristic parameters of preferential flow. The matrix flow of grassland was superior to that of secondary forestland, whereas the preferential flow of the secondary forestland was better than other stand origins, and plantation forestland can effectively reduce the degree of preferential flow. Preferential and matrix flows have a large influence on the accumulation of available nutrients and organic matter under plantation forestland, secondary forestland, and natural grassland, or infiltration water volumes, indicating that preferential flow may affect the distribution of soil nutrients and the growth of surface vegetation by influencing the distribution of soil nutrients. Reasonable allocation of plantation forests has a certain mitigation effect on soil erosion in Karst areas, and preferential flow under this special geomorphological type is worth studying. Preferential flow can transport nutrients to deeper soil for roots according to the data of this study. Therefore, plantation is feasible under karst landform conditions, but it is better to combine herbaceous plants in a plantation. The results could 
provide suggestions for the restoration of rocky desertification and the advantages or disadvantages of vegetation restoration engineering in karst areas.

Author Contributions: Conceptualization, X.K., J.C., and X.H.; methodology, X.K.; software, X.K.; validation, X.K., F.Z., and M.L.; formal analysis, X.K.; investigation, X.K., F.Z., and M.L.; resources, X.K.; data curation, X.K.; writing-original draft preparation, X.K.; writing-review and editing, X.K.; visualization, X.K.; supervision, X.K.; project administration, J.C. and X.H.; funding acquisition, J.C. and X.H.

Funding: This research was funded by The National Basic Program of China, grant No. 2017YFC0505504.

Acknowledgments: Many thanks to the Jian Shui Forestry Station for offering accommodation and supporting field experiments. Meanwhile, we gratefully acknowledge the editor and reviewers.

Conflicts of Interest: The authors declare no conflict of interest.

\section{References}

1. Jarvis, N.J. A review of non-equilibrium water flow and solute transport in soil macropores: Principles, controlling factors and consequences for water quality. Eur. J. Soil Sci. 2007, 58, 523-546. [CrossRef]

2. Cheng, J.; Wu, J.; Chen, Y.; Zhang, H. Characteristics of preferential flow paths and their effects on soil properties. For. Chron. 2014, 90, 192-196. [CrossRef]

3. Flühler, H.; Durner, W.; Flury, M. Lateral solute mixing processes-A key for understanding field-scale transport of water and solutes. Geoderma 1996, 70, 165-183. [CrossRef]

4. Lin, H. Linking principles of soil formation and flow regimes. J Hydrol. 2010, 393, 3-19. [CrossRef]

5. Guo, L.; Lin, H. Addressing two bottlenecks to advance the understanding of preferential flow in soils. Adv. Agron. 2018, 147, 61-117.

6. Wang, X.P.; Li, X.R.; Xiao, H.L.; Berndtsson, R.; Pan, Y.X. Effects of surface characteristics on infiltration patterns in an arid shrub desert. Hydrol. Process. 2007, 21, 72-79. [CrossRef]

7. Somaratne, N. Characteristics of point recharge in karst aquifers. Water 2014, 6, 2782-2807. [CrossRef]

8. Zhang, Z.; Wang, W.; Qu, S.; Huang, Q.; Liu, S.; Xu, Q.; Ni, L. A new perspective to explore the hydraulic connectivity of karst aquifer system in Jinan spring catchment, China. Water 2018, 10, 1368. [CrossRef]

9. Šimůnek, J.; Van Genuchten, M.T.; Šejna, M. Development and applications of the HYDRUS and STANMOD software packages and related codes. Vadose Zone J. 2008, 7, 587-600. [CrossRef]

10. Wang, P.; Zeng, L.; Huai, W. Transient dispersion of an initial point pollutant concentration in wetland flows. Environ. Sci. Pollut. Res. 2018, 25, 34414-34425. [CrossRef]

11. Clothier, B.E.; Green, S.R.; Deurer, M. Preferential flow and transport in soil: progress and prognosis. Eur. J. Soil Sci. 2008, 59, 2-13. [CrossRef]

12. Wang, P.; Chen, G.Q. Solute dispersion in open channel flow with bed absorption. J. Hydrol. 2016, 543, 208-217. [CrossRef]

13. Wang, F.; Chen, H.; Lian, J.; Fu, Z.; Nie, Y. Preferential flow in different soil architectures of a small karst catchment. Vadose Zone J. 2018, 17. [CrossRef]

14. Green, R.T.; Bertetti, F.P.; Miller, M.S. Focused groundwater flow in a carbonate aquifer in a semi-arid environment. J. Hydrol. 2014, 517, 284-297. [CrossRef]

15. Allaire, S.E.; Bochove, E.V.; Denault, J.T.; Dadfar, H.; Thériault, G.; Charles, A.; De Jong, R. Preferential pathways of phosphorus movement from agricultural land to water bodies in the Canadian Great Lakes basin: A predictive tool. Can. J. Soil Sci. 2011, 91, 361-374. [CrossRef]

16. Lipsius, K.; Mooney, S.J. Using image analysis of tracer staining to examine the infiltration patterns in a water repellent contaminated sandy soil. Geoderma 2006, 136, 865-875. [CrossRef]

17. Turpin, K.M.; Lapen, D.R.; Topp, E. Tine-influenced infiltration patterns and informing timing of liquid amendment applications using brilliant blue dye tracers. Biosyst. Eng. 2007, 98, 235-247. [CrossRef]

18. Anaya, A.A.; Padilla, I.; Macchiavelli, R. Estimating preferential flow in karstic aquifers using statistical mixed models. Groundwater 2014, 52, 584-596. [CrossRef] [PubMed]

19. Somaratne, N.; Mustafa, S.; Lawson, J. Use of hydrochemistry, stable isotope, radiocarbon, ${ }^{222} \mathrm{Rn}$ and terrigenic ${ }^{4} \mathrm{He}$ to study the geochemical processes and the mode of vertical leakage to the Gambier Basin tertiary confined sand aquifer. South Australia. Water 2016, 8, 180. [CrossRef] 
20. Liu, M.X.; Du, W.Z.; Zhang, H.L. Changes of preferential flow path on different altitudinal zones in the three gorges reservoir area, China. Can. J. Soil Sci. 2014, 94, 177-188. [CrossRef]

21. Jarvis, N.; Larsbo, M.; Koestel, J. Connectivity and percolation of structural pore networks in a cultivated silt loam soil quantified by X-ray tomography. Geoderma 2017, 287, 71-79. [CrossRef]

22. Edwards, W.M.; Shipitalo, M.J.; Owens, L.B.; Dick, W.A. Factors affecting preferential flow of water and atrazine through earthworm burrows under continuous no-till corn. J. Environ. Qual. 1993, 22, 453-457. [CrossRef]

23. Bogner, C.; Borken, W.; Huwe, B. Impact of preferential flow on soil chemistry of a podzol. Geoderma 2012, 175, 37-46. [CrossRef]

24. Costa, D.; Pomeroy, J.W. Preferential meltwater flowpaths as a driver of preferential elution of chemicals from melting snowpacks. Sci. Total Environ. 2019, 662, 110-120. [CrossRef]

25. Wang, P.; Chen, G.Q. Contaminant transport in wetland flows with bulk degradation and bed absorption. J. Hydrol. 2017, 552, 674-683. [CrossRef]

26. Wang, P.; Zeng, L. On the bicomponent contaminant transport in wetland flow with reactions. J. Hydrol. 2019, 576, 541-550. [CrossRef]

27. Morris, C.; Mooney, S.J. A high-resolution system for the quantification of preferential flow in undisturbed soil using observations of tracers. Geoderma 2004, 118, 133-143. [CrossRef]

28. Peyton, R.L.; Haeffner, B.A.; Anderson, S.H.; Gantzer, C.J. Applying X-ray CT to measure macropore diameters in undisturbed soil cores. Geoderma 1992, 53, 329-340. [CrossRef]

29. Zeng, Y.; Payton, R.L.; Gantzer, C.J.; Anderson, S.H. Fractal dimension and lacunarity of bulk density determined with X-ray computed tomography. Soil Sci. Soc. Am. J. 1996, 60, 1718-1724. [CrossRef]

30. Radulovich, R.; Solorzano, E.; Sollins, P. Soil macropore size distribution from water breakthrough curves. Soil Sci. Soc. Am. J. 1989, 53, 556-559. [CrossRef]

31. Holden, J. Flow through macropores of different size classes in blanket peat. J. Hydrol. 2009, 364, 342-348. [CrossRef]

32. Stumpp, C.; Maloszewski, P. Quantification of preferential flow and flow heterogeneities in an unsaturated soil planted with different crops using the environmental isotope 818 O. J. Hydrol. 2010, 394, 407-415. [CrossRef]

33. Pang, D.; Wang, G.; Li, G.; Sun, Y.; Liu, Y.; Zhou, J. Ecological stoichiometric characteristics of two typical plantations in the karst ecosystem of Southwestern China. Forests 2018, 9, 56. [CrossRef]

34. Chen, H.; Hu, K.; Nie, Y. Analysis of soil water movement inside a footslope and a depression in a karst catchment, Southwest China. Sci. Rep. 2017, 7, 2544. [CrossRef] [PubMed]

35. Zhang, X.; Hu, M.; Guo, X.; Yang, H.; Zhang, Z.; Zhang, K. Effects of topographic factors on runoff and soil loss in Southwest China. Catena 2018, 160, 394-402. [CrossRef]

36. Mei, X.; Zhu, Q.; Ma, L. Effect of stand origin and slope position on infiltration pattern and preferential flow on a Loess hillslope. Land Degrad. Dev. 2018, 29, 1353-1365. [CrossRef]

37. Alaoui, A.; Caduff, U.; Gerke, H.H. A preferential flow effects on infiltration and runoff in grassland and forest soils. Vadose Zone J. 2011, 10, 367-377. [CrossRef]

38. Hagedorn, F.; Bundt, M. The age of preferential flow paths. Geoderma 2002, 108, 119-132. [CrossRef]

39. Yao, J.; Cheng, J.; Sun, L. Effect of antecedent soil water on preferential flow in four soybean plots in Southwestern China. Soil Sci. 2017, 182, 83-93. [CrossRef]

40. Flury, M.; Flühler, H. Brilliant Blue FCF as a dye tracer for solute transport studies-A toxicological overview. J. Environ. Qual. 1994, 23, 1108-1112. [CrossRef]

41. Van Schaik, N. Spatial variability of infiltration patterns related to site characteristics in a semi-arid watershed. Catena 2009, 78, 36-47. [CrossRef]

42. Sollins, P.; Radulovich, R. Effects of soil physical structure on solute transport in a weathered tropical soil. Soil Sci. Soc. Am. J. 1988, 52, 1168-1173. [CrossRef]

43. Bargués Tobella, A.; Reese, H.; Almaw, A. The effect of trees on preferential flow and soil infiltrability in an agroforestry parkland in semiarid Burkina Faso. Water Resour. Res. 2014, 50, 3342-3354. [CrossRef] [PubMed]

44. Wu, Q.; Zhang, J.; Lin, W. Appling dyeing tracer to investigate patterns of soil water flow and quantify preferential flow in soil columns. Trans. Chin. Soc. Agric. Eng. 2014, 30, 82-90. 
45. Sheng, F.; Wang, K.; Zhang, R.D. Study on heterogeneous characteristics of soil water flow in field by dye tracing method. J. Hydraul. Eng 2009, 40, 101-108.

46. Vere, D.T.; Griffith, G.R. Structural econometric modelling in Australia's livestock production and marketing systems: the potential benefits of model integration for industry analysis. Agric. Syst. 2004, 81, 115-131. [CrossRef]

47. Song, X.Y.; Lee, S.Y. Bayesian analysis of structural equation models with nonlinear covariates and latent variables. Multivar. Behav. Res. 2006, 41, 337-365. [CrossRef]

48. Wei, X.; Bi, H.; Liang, W.; Hou, G.; Kong, L.; Zhou, Q. Relationship between Soil Characteristics and Stand Structure of Robinia pseudoacacia L. and Pinus tabulaeformis Carr. Mixed Plantations in the Caijiachuan Watershed: An Application of Structural Equation Modeling. Forests 2018, 9, 124. [CrossRef]

49. Van Ommen, H.C.; Dijksma, R.; Hendrickx, J.M.H. Experimental assessment of preferential flow paths in a field soil. J. Hydrol. 1989, 105, 253-262. [CrossRef]

50. Bogner, C.; Wolf, B.; Schlather, M. Analysing flow patterns from dye tracer experiments in a forest soil using extreme value statistics. Eur. J. Soil Sci. 2008, 59, 103-113. [CrossRef]

51. Sohrt, J.; Ries, F.; Sauter, M. Significance of preferential flow at the rock soil interface in a semi-arid karst environment. Catena 2014, 123, 1-10. [CrossRef]

52. Chen, X.B.; Zhang, H.J.; Cheng, J.H. Quantitative evaluation of preferential flow development degree based on dyed image variability analysis. Trans. CSAM 2015, 46, 93-100.

53. Jiang, X.; Liu, X.; Wang, E. Effects of tillage pan on soil water distribution in alfalfa-corn crop rotation systems using a dye tracer and geostatistical methods. Soil Tillage Res. 2015, 150, 68-77. [CrossRef]

54. Zhang, Y.; Niu, J.; Zhang, M. Interaction between plant roots and soil water flow in response to preferential flow paths in northern China. Land Degrad. Dev. 2017, 28, 648-663. [CrossRef]

55. Shinohara, Y.; Otsuki, K. Comparisons of soil-water content between a Moso bamboo (Phyllostachys pubescens) forest and an evergreen broadleaved forest in western Japan. Plant Species Biol. 2015, 30, 96-103. [CrossRef]

56. Wang, P.; Chen, G.Q. Environmental dispersion in a tidal wetland with sorption by vegetation. Commun. Nonlinear Sci. Numer. Simul. 2015, 22, 348-366. [CrossRef]

57. Julich, S.; Benning, R.; Julich, D. Quantification of phosphorus exports from a small forested headwater-catchment in the Eastern Ore Mountains, Germany. Forests 2017, 8, 206. [CrossRef]

58. Hewelke, E.; Oktaba, L.; Gozdowski, D.; Kondras, M.; Olejniczak, I.; Górska, E. Intensity and persistence of soil water repellency in pine forest soil in a temperate continental climate under drought conditions. Water 2018, 10, 1121. [CrossRef]

59. Huggett, R.J. Soil chronosequences, soil development, and soil evolution: A critical review. Catena 1998, 32, 155-172. [CrossRef]

60. Julich, D.; Julich, S.; Feger, K.H. Phosphorus in preferential flow pathways of forest soils in Germany. Forests 2016, 8, 19. [CrossRef]

(C) 2019 by the authors. Licensee MDPI, Basel, Switzerland. This article is an open access article distributed under the terms and conditions of the Creative Commons Attribution (CC BY) license (http://creativecommons.org/licenses/by/4.0/). 